\title{
¿QUÉ SISTEMA DE PROTECCIÓN PARA LAS INNOVACIONES BIOTECNOLÓGICAS EN AMÉRICA LATINA?
}

\author{
Salvador Darío Bergel ${ }^{*}$ \\ s.bergel@ezabog.com.ar
}

\begin{abstract}
RESUMEN
El presente artículo examina las ventajas e inconvenientes de una protección "fuerte" de los derechos de propiedad industrial relativos a biotecnología en Latinoamérica. La reciente experiencia en el campo de la propiedad intelectual -en general- y de la propiedad industrial en particular- muestra un sostenido avance en la protección brindada, lo que ha beneficiado a los países centrales, que poseen un mayor potencial en ciencia y tecnología. Frente a esta situación, los países subdesarrollados no han sido oídos en sus reclamos (transferencia de tecnología, protección de sus recursos genéticos y conocimientos tradicionales). Tomando en cuenta este desbalance, una protección "fuerte" de los derechos intelectuales sólo puede contribuir a acrecentar la brecha existente, en perjuicio de los países subdesarrollados.
\end{abstract}

Palabras Claves: transferencia de tecnología; biotecnología; recursos genéticos; patentes de invención.

\section{What protection system for the biotechnology innovations in Latin America?}

\section{ABSTRACT}

The current article examines the advantages and inconveniences of a "substantial" protection of the industrial property rights and referring to the biotechnology in Latin America. The recent experience in the field of intellectual property - in general - and the industrial property in particular - shows a continuous advancement in the pledge protection that has benefited the central countries that possess a major potential in science and technology. At the head of this situation, the developing countries have not been heard in their demands (technology transfer, genetics resources of their protection and traditional knowledge). Taking into account such imbalance, a "substantial" protection of the intellectual rights only can contribute to increase the existent gap in disadvantage to the developing countries.

Key words: technology transfer; biotechnology; genetics resources; patent of invention

\footnotetext{
* Director de la Cátedra de Bioética de la Unesco de la Universidad Nacional de Buenos Aires i Catedràtic de ret Mercantil de la Universidad de Buenos Aires.
} 


\section{FINES Y FUNDAMENTOS DE LOS DERECHOS DE PROPIEDAD INDUSTRIAL}

Los derechos de propiedad industrial nacieron como un estímulo para la actividad creativa de los hombres, al otorgarle al inventor un privilegio - traducido en la concesión de un derecho de exclusiva- que les permitiera obtener durante un periodo determinado de tiempo una renta monopólica.

Históricamente se los consideró un derecho natural del inventor y en algunas oportunidades se habló de un verdadero derecho humano a gozar de una recompensa por los beneficios aportados a la sociedad por la introducción del invento.

En una visión actual se los considera como un instrumento de la política pública que otorga privilegios a particulares o instituciones, únicamente con el propósito de contribuir al bien de la sociedad en su conjunto. Este privilegio es por tanto un medio para conseguir un fin y no un fin en si mismo².

Durante largo tiempo la figura dominante en torno a estos derechos fue la del “inventor”. Toda la estructura normativa tendía a establecer un verdadero "estatuto del inventor” que le asignaba derechos y lo protegía ante las infracciones por copias, reproducción, etc.

A medida que los procesos de desarrollo económico fueron avanzando en las naciones industrializadas y que se abrieron nuevos mercados en los que se pudo apreciar el valor de la innovación tecnológica se produjo un viraje en cuanto a la fundamentación de estos derechos y la figura clásica del “inventor” quedó desplazada por la del “inversor”. El creciente patentamiento de tecnología de punta por parte de empresas cada vez más poderosas importó un cambio importante que hoy amenaza minar las bases de sustentación del sistema ${ }^{3}$.

Diversos fundamentos se han ensayado para justificar los derechos de propiedad industrial. Dejando de lado los que se basan en derecho personales o naturales vamos a referirnos a los que se vinculan con las bases económicas: desarrollo de la capacidad

\footnotetext{
${ }^{2}$ Informe de la Comisión sobre "Derechos de la propiedad intelectual: integrando los derechos de propiedad y las políticas de desarrollo", en Temas de derecho industrial y la competencia, $\mathrm{N}^{\circ} 7$, edit. Ciudad Argentina, Buenos Aires 2005, pág. 47. La Comisión sobre derechos de propiedad industrial fue creada por la Secretaría de Estado para el Desarrollo Industrial del gobierno británico en mayo de 2001 y está integrada por los doctores John Burton (presidente), Daniel Alexander, Carlos Correa, Rames Mashelkar, Gill Samels y Sandy Thomas.

${ }^{3} \mathrm{Al}$ hablar de "sistema" nos referimos al conjunto de normas legales, decisiones administrativas de la Oficina de Patentes y decisiones judiciales que gobiernan en la materia.
} 
tecnológica y transferencia de tecnología; incremento de las inversiones extranjeras y desarrollo de la investigación y de la capacitación científica en los países que los reconocen.

Con relación al desarrollo de la capacidad tecnológica y a la transferencia de tecnología por parte de los países industrializados a los subdesarrollados, se han tejido una serie de teorías cuya verificación es harto discutible. Aquí hay que tomar fundamentalmente en consideración la diversa posición relativa de los países exportadores de tecnología y la de los receptores.

Para los países subdesarrollados, al igual que lo que ocurrió con los países industrializados en el pasado, el desarrollo de su propia capacidad tecnológica constituye un factor determinante para el crecimiento económico y la reducción de la pobreza. Muchos estados han llegado a la conclusión que el factor más importante para determinar el éxito de la transferencia de tecnología es la aplicación precoz de una capacidad tecnológica autóctona (PROPIEDAD INTELECTUAL Y POLÍTICAS DE DESARROLLO, 2005).

Respecto a la región latinoamericana la experiencia empírica muestra que es un destino relativamente menor de las solicitudes globales de patente. La región otorga menos del 2\% del total global y paralelamente los residentes en América Latina solicitan pocas patentes en el extranjero, representando en el caso de los Estados Unidos (líder mundial) menos del 0,5 \% de todas las solicitudes de la Oficina de Patentes de los Estados Unidos (USPTO). Esto refleja la baja actividad inventiva de la región y paralelamente el negligente uso de la información contenida en las patentes (ROFFE, 2005). Estas circunstancias deben ser tomadas en consideración al pronunciarnos sobre las ventajas o inconvenientes de un sistema abierto de protección patentable.

Con relación al incremento de la inversión extranjera como consecuencia de la concesión de patentes o de la suscripción de acuerdos bilaterales que expandan la protección patentaria, no se han obtenido evidencias que avalen esta postura. Brasil, Nigeria y China demostraron que aún no siendo parte en ningún tratado de inversiones, tuvieron desde hace algunos años un fuerte crecimiento en el flujo de inversión extranjera directa, mientras que países centro africanos y centro americanos que han firmado nuevos acuerdos de inversión, tuvieron un pequeño flujo de inversión extranjera (PETERSON, 2004).

No existen indicios suficientes que indiquen que en la mayoría de los países en desarrollo las inversiones extranjeras estén vinculadas a la protección de la propiedad industrial. 
La mayor parte de la evidencia sobre cómo influye la propiedad industrial en el comercio y en la inversión está referida a los países en desarrollo más avanzados tecnológicamente. Para el resto de los países es poco probables que los efectos positivos en el comercio y las inversiones tenga un mayor peso que los costos que originan, por lo menos a corto y mediano plazo (PROPIEDAD INTELECTUAL Y POLÍTICAS DE DESARROLLO, 2005, p. 56).

\section{CARACTERÍSTICAS DEL SISTEMA ACTUAL DE PROPIEDAD INDUSTRIAL A NIVEL GLOBAL}

Tal como hemos señalado el sistema de propiedad industrial es de naturaleza territorial. No obstante ello en el pasado reciente hemos asistido a un proceso progresivo de universalización y armonización promovido por los países industrializados -especialmente por parte de los Estados Unidos- que apuntan a armonizar las normas regulatorias desconociendo las diferencias relativas y tratando de imponer al mundo sus propios normas sobre propiedad industrial.

El intento mejor logrado de esta tendencia es el acuerdo TRIPS del GATT, al que se incorporaron en un acuerdo multinacional de comercio una serie de principios sustanciales y adjetivos destinados a reforzar notablemente los poderes de los países industrializados en detrimento de los subdesarrollados.

Entre los principios incorporados en el acuerdo tenemos:

a) Duración de las patentes por un plazo no menor a veinte años.

b) Protección de todas las ramas de la tecnología con lo cual se sustrajo a la mayor parte de los países subdesarrollados la excepción de patentamiento de los medicamentos.

c) La incorporación de la cláusula de la nación más favorecida en función de la cual cualquier ventaja concedida a los nacionales de cualquier otro país, se otorga inmediatamente y sin condiciones a todos los demás nacionales de los miembros de la OMC.

d) La adopción de normas adjetivas que impulsan una efectiva y total protección a través de medidas de fronteras, sanciones comerciales, etc. 
Al suscribirse el Acuerdo TRIPS se establecieron algunas cláusulas de salvaguardia para tratar de equilibrar las duras condiciones impuestas a los países en desarrollo; entre ellas las contenidas en el artículo $7^{\circ}$ al establecer los objetivos y el $8^{\circ}$ en los principios generales.

Los países en desarrollo aceptaron el Acuerdo TRIPS no porque la opción de una protección amplia haya sido una solución favorable a sus intereses, sino por la presión que ejercieron los países desarrollados, postura que no se vio correspondida por ventajas concedidas a estos países.

Tal como lo recuerda Correa el principal argumento para establecer altos patrones internacionales para los derechos de propiedad industrial fue el supuesto impacto positivo que esos derechos tendrían sobre la innovación. Los derechos de propiedad industrial más amplios y más fuertes promoverían la creatividad y la innovación a escala mundial. Esto justificaría que la comunidad internacional y particularmente los países subdesarrollados asumieran los costos asociados a la concesión de tales derechos (CORREA, 2005, p. 37).

Lo cierto es que a diez años de vigencia del Acuerdo los grandes perdedores fueron los países subdesarrollados, ya que la transferencia de tecnología sigue siendo un objetivo por alcanzar mientras los derechos de propiedad industrial han crecido cuantitativamente y los criterios de patentamiento se han flexibilizado al extremo en las prácticas de las oficinas de patentes ${ }^{4}$.

Por otra parte, los temas que hubieran llegado a beneficiar a los países subdesarrollados (por ejemplo la reforma del artículo 27 3b)) con lo cual se llegaría a establecer un cierto equilibrio entre el Acuerdo TRIPS y la Convención de Biodiversidad, están aún en ciernes.

Logrados los objetivos iniciales, los Estados Unidos vienen desarrollando una intensa presión política, económica y diplomática para establecer un sistema TRIPS-plus que

\footnotetext{
${ }^{4}$ Jeffrey Sachs considera que debemos examinar abordajes nuevos y más dinámicos para la transferencia de tecnología de los países ricos para los pobres. Llama la atención que muchos tratados y declaraciones internacionales identificaran la transferencia de tecnología como uno de los objetivos del sistema internacional. Entretanto, existe muy poco acompañamiento operativo a lo largo de todo el proceso. ¿Qué tipo de programas pueden promover la transferencia de tecnología? ¿Cuál es la mejor manera de monitorearlo? Para algunos países pobres, al menos, esta es una cuestión de vida o muerte en cuanto los países ricos lo consideran un asunto sin importancia. Los países pobres piden que los países ricos comiencen a tomar en serio algunos compromisos internacionales en esa área, firmados hace bastante tiempo, más hasta ahora no obtuvieron respuesta alguna (J. Sachs: El divisor global de innovación, en VARELLA, 2005, p. 21).
} 
mediante acuerdos de libre comercio o de inversiones boicotean el sistema multilateral para llegar a consagrar un sistema bilateral mucho más gravoso aún para los intereses de los países subdesarrollados ${ }^{5}$.

Esto nos muestra que conforme a las cambiantes corrientes de interés se obliga a los países subdesarrollados a aceptar un régimen multilateral (tal el caso del Acuerdo TRIPS) o se los empuja hacia un sistema bilateral más gravoso. Lo cierto es que la presión por el reconocimiento de derechos de propiedad intelectual cada vez más extensos, es creciente.

Si a ello sumamos los esfuerzos que se realizan en el seno de la OMPI para establecer un sistema amplio de protección a nivel universal, podremos tener una idea más clara de cuanto afirmamos más arriba. Existe el peligro que la propiedad industrial pase de ser un instrumento de innovación y desarrollo tecnológico a ser una barrera proteccionista a favor de empresas dominantes, es decir un factor, bien de restricción de la oferta, bien de ralentización de los procesos productivos de innovación (GHIDINI, 2002, p. 13).

Para completar el cuadro de situación hay que tomar en cuenta las asimetrías fundamentales que existen entre los países desarrollados y los subdesarrollados, asimetría que a través del tiempo se acentúa en tanto el acceso a las tecnologías de punta se torna cada vez más distante para estos y los problemas diarios hacen que puedan dedicar pocos recursos a inversión y desarrollo.

\section{EL GRADO ÓPTIMO DE PROTECCIÓN DE LA PROPIEDAD INDUSTRIAL}

Para establecer el grado óptimo de protección de los derechos de propiedad industrial hay que partir del reconocimiento que el derecho de exclusiva otorgado al titular de la patente importa al mismo tiempo una limitación a la competencia. Se fragmenta un sector determinado del amplio campo de libertad de comercio para otorgárselo en exclusiva a un sujeto.

Si el beneficio social recibido por la divulgación de la patente es equivalente a la afectación de la competencia en ese campo, el equilibrio entre competencia y derechos del inventor no se ve alterado. Si por el contrario la concesión de los derechos de exclusiva

\footnotetext{
${ }^{5}$ Con una cantidad cada vez mayor de acuerdos de libre comercio de los Estados Unidos que acuerdan un acceso preferencial al mercado norteamericano de bienes a diferentes países, aquéllos que quedan fuera sentirán una mayor presión económica por celebrar acuerdos similares y así estarán cada vez más dispuestos a aceptar los estándares de los Estados Unidos de protección de la propiedad industrial (DREXL, 2005)
} 
produce perjuicios a la sociedad, el equilibrio se rompe en beneficio de uno de los actores. Tal es el caso de concesión de patentes sin un efectivo aporte inventivo, lo que desorbita sobradamente el aporte realizado por el inventor.

La protección se funda -entre otras razones- en una especie de pacto entre el inventor y la sociedad que apunta al logro de un mayor nivel de innovación tecnológica. Si la protección es demasiado débil, el desarrollo de la tecnología puede verse obstaculizado dado que no existirían suficientes incentivos para la investigación y el desarrollo.

Por el contrario si la protección es excesiva, los consumidores saldrán perjudicados a largo plazo, y los titulares de patentes obtendrán beneficios que excederán en mucho los costos generales de investigación y desarrollo, a más de entorpecer la invención futura basada en la tecnología protegida (PROPIEDAD INTELECTUAL Y POLÍTICAS DE DESARROLLO , 2005, p. 61). La visión simplista de que la protección intensa de propiedad intelectual necesariamente lleva a mayor innovación y a futuros beneficios a la sociedad es, a juicio de Correa, teórica y empíricamente insostenible (CORREA, 2005, p. 47).

Un sistema óptimo debe tender a un equilibrio adecuado entre los actores, tratando que los beneficios acordados no superen a los costos.

Los académicos, sobre todos los economistas, tradicionalmente han sido críticos con los derechos de propiedad industrial. Estos derechos normalmente imponen restricciones a la competencia que pueden perjudicar a los consumidores y a la libertad de comercio. La cuestión estriba en determinar si los incentivos para la investigación y la invención tienen un mayor peso que esos costos (PROPIEDAD INTELECTUAL Y POLÍTICAS DE DESARROLLO, 2005, p. 68).

Thurow sostiene que en una economía global se requiere un sistema mundial de propiedad industrial. Este sistema debe reflejar las necesidades tanto de los países en desarrollo como los países desarrollados. Dando un ejemplo de lo dicho, expresa Thurow que la necesidad del tercer mundo de obtener productos farmacéuticos de bajo costo no es equivalente a sus necesidades de discos compactos. Un sistema que trate a ambas necesidades de la misma forma, como lo hace nuestro sistema actual, no es bueno ni viable (THUROW, 1997, p. 66).

El sector productivo de las “innovaciones biotecnológicas” ha reclamado reiteradamente "fuertes" derechos de propiedad intelectual.

"Fuerte" en este contexto -apunta Stiglitz- puede ser equivalente a bueno con la 
implicación que cuanto “más fuerte”, mejor.

Sin embargo -agrega Stiglitz- el asunto es mucho más complejo. Más “fuerte” en el sentido de una protección “más rigurosa” podría tener no sólo graves consecuencias distributivas (digamos entre países desarrollados y países menos desarrollados) sino también graves consecuencias para la eficiencia al impedir en realidad el ritmo de innovación y reducirse los niveles de vida entre los países menos desarrollados (STIGLITZ , 1999, p. 328).

En el actual contexto mundial una protección "fuerte" en innovaciones biotecnológicas implica aceptar los criterios que en líneas generales comparte los Estados Unidos, la Unión Europea y Japón, es decir desnaturalizar los recaudos de novedad, mérito inventivo y actividad industrial, conceder patentes sobre descubrimientos, sobre genes, sobre plantas, microorganismos en estado natural y admitir reivindicaciones amplias y funcionales que exceden el aporte realizado por el titular.

Tal como preconiza Ghidini (2002) un sistema moderno de propiedad intelectual dirigido a estimular la constante innovación debe buscar un equilibrio dinámico que evite a la vez los peligros de duplicación de la free-reading y la proliferación de monopolios mal concedidos que otorguen a los monopolios rentistas una situación de control y sofoquen las futuras inversiones.

Considerado en la órbita de la políticas económicas de los estados, un sistema "fuerte" de la propiedad industrial que en los hechos implique una apertura irrestricta a la concesión de patentes y que someta al dominio privado extensas áreas del conocimiento o de innovaciones en sus etapas incipientes, cuando aún no han llegado a ser socialmente útiles, no es un camino recomendable para los países subdesarrollados.

La distinción entre invento (patentable) y descubrimiento (excluido de la protección) así como la observancia de los requisitos objetivos de patentabilidad (novedad, altura o mérito inventivo y aplicación industrial) de general aceptación en los diversos regímenes de propiedad industrial sin extralimitaciones o extensiones que los deformen o desnaturalicen constituye no sólo un logro histórico del derecho de la propiedad industrial, sino que se relaciona con las bases económicas y filosóficas en las que se apoya.

Apartarse de este esquema es peligroso en tanto se pueden constituir monopolios que no reditúen socialmente y que sólo atienda a los intereses sectoriales de quienes lo detenten. En este sentido compartimos el aserto de Chauveau (2004, p. 105) en cuanto considera que el refuerzo de la patente no se puede justificar más que si implica un aporte a la 
mejora del bienestar general.

\section{LA PROTECCIÓN DE LAS INNOVACIONES EN EL CAMPO DE LA BIOTECNOLOGÍA LA EMERGENCIA DE LA BIOTECNOLOGÍA MODERNA}

Para ubicarnos en el tema propuesto, considero importante introducirnos en el reciente desarrollo de la ciencia y de la técnica, en un plano convergente. La diferenciación entre ciencia y técnica, aparentemente simple, está hoy cuestionada por el creciente entramado de las ciencias naturales y de la técnica que se manifiesta tanto en una tecnificación de la ciencia, como en una cientifización de la técnica ${ }^{6}$.

Esta nueva relación dio nacimiento a la categoría de las tecnociencias, categoría que exhibe la íntima conexión entre ambos saberes. En esta dirección el neologismo “biotecnociencias”, propuesto por Schramm, traslada esta conexión al campo de las ciencias de la vida.

Paralelamente, las relaciones entre ciencia y técnica que proceden de la sociedad industrial se vieron considerablemente reforzadas por la emergencia de la macrociencia, categoría que impactó sobre la economía al convertirse la gran empresa en un factor decisivo para el financiamiento de las investigaciones tecnocientíficas. (ECHEVERRÍA, 2003, p. 66).

El acceso de los operadores económicos en este terreno condujo a la manifestación de un fenómeno novedoso: que los resultados de la actividad tecnocientífica se conviertan en una mercancía, sometida a las leyes del mercado. La creciente privatización del conocimiento incorporado o resultante de la investigación rompió el sistema que a partir del iluminismo permitió el avance de las ciencias: el de la libre circulación del conocimiento ${ }^{7}$.

Hoy, al ser considerado y tratado el conocimiento científico como mercancía, adquiere un valor económico de cambio con independencia de su concreta aplicación industrial. Es que la economía post industrial está fundada, entre otros pilares básicos, en el conocimiento y la información (FRANCESCHI, 2004, p. 116).

\footnotetext{
${ }^{6}$ Stork, H., cit., por HOTTOIS (1991, p. 20).

${ }^{7}$ La apropiación del conocimiento no es del objeto construido a partir del conocimiento, sino del conocimiento en sí. Es verdad que el debate actual transita sobre la cuestión de saber si se podría apropiar directamente el conocimiento y no sólo los objetos producidos por él, pero no hay necesidad de entrar en esta discusión para recordar que el objeto no está protegido más que en tanto vector del acrecentamiento del conocimiento que ha nacido del espíritu del inventor (Frison Roche, M. A. Les biens de'humanite débouche de la querelle entre marché et patrimonie, en VIVANT, M. (dir): pág. 165.
} 
Desde una perspectiva axiológica cabe afirmar que con la llegada de las tecnociencias los valores más característicos del capitalismo entraron en el núcleo mismo de la actividad científico-tecnológica. La tecnociencia -conforme lo enseña Echeverríaincorpora a su núcleo axiológico buena parte de los valores técnicos (utilidad, eficacia, eficiencia, funcionalidad, aplicabilidad, etc.) y aunque sigue manteniendo los valores epistémicos, el segundo subsistema de valores toma un peso tan considerable como el primero (ECHEVERRÍA, 2003, p. 67).

El predominio de los intereses del mercado constituye una característica singular y dominante en el nuevo escenario de las tecnociencias, lo que contribuye al trazado de un nuevo mapa del universo, cada vez más definido, que muestra un grupo minúsculo de países desarrollados, propietarios en gran medida de la ciencia y de la técnica, que las utilizan para acrecentar su dominio sobre los países subdesarrollados que se ven cada vez más alejados del mundo de la innovación, lo que les retarda -o simplemente les imposibilita- un desarrollo aceptable que les permita mejorar las condiciones de vida de millares de seres.

Las consecuencias de tan dispar distribución de oportunidades se pueden igualmente apreciar con el crecimiento de la pobreza y de la exclusión social en el mundo subdesarrollado.

Descendiendo al campo específico de nuestro análisis -el de la biotecnologíacabe aquí recordar una admonitoria advertencia de Francois Gross formulada hace dos décadas: “en los próximos veinte años las tecnologías de la vida tendrán un lugar importante no sólo para la transferencia y aplicación de conocimientos nuevos que llegan desde investigaciones básicas o aplicadas, sino también para formular y permitir ellas mismas estos conocimientos” (GROS, 1979, p. 119).

Los avances experimentados por la biología y otras disciplinas vinculadas a ella (biología molecular, biología celular, bioquímica, microbiología, genética) en la segunda mitad de siglo que dejamos y que continúa con igual o mayor ritmo en el presente, no sólo ha renovado la mayor parte de los conocimientos que poseíamos con relación a los seres vivos, sino que -paralelamente- han contribuido a generar una serie de aplicaciones prácticas llamadas a provocar un cambio decisivo en nuestra existencia.

La biotecnología moderna no sólo constituye una profunda revolución en el campo científico-tecnológico, sino que paralelamente ha impulsado una de las grandes y prometedoras revoluciones en el campo de la economía, a punto tal que no existe rama de la 
actividad económica que haya quedado al margen de sus logros: agricultura, ganadería, biorremediación, alimentos, fármacos, procesos industriales, etc.

De allí que no sólo cabe analizar sus logros en el campo del conocimiento, sino que es tan o más importante analizarlos como motor del desarrollo.

La incontenible revolución que produjo la agricultura transgénica, constituye una prueba contundente de cuanto señalamos. Hoy una parte considerable de la agricultura mundial se maneja con semillas transgénicas, lo que produce una considerable renta monopólica a las empresas semilleras, en su mayoría multinacionales.

Lo destacable en este caso es que los países del tercer mundo no han sido protagonistas destacados de estos significativos avances, ya que los beneficios obtenidos no se han proyectado en su provecho, sino que por el contrario se ha acentuado la dependencia científico-tecnológica en detrimento de sus legítimos intereses.

\section{EL ARROLLADOR AVANCE DE LOS DERECHOS INTELECTUALES}

La evolución de la biotecnología se ha dado en coincidencia con una serie de transformaciones en el campo de los derechos intelectuales, lo que contribuyó a hacer más visible la asimetría generada en el orden internacional.

En su curso más reciente los derechos de la propiedad industrial (DPI) -de esta categoría estamos hablando cuando nos referimos aquí a los derechos intelectuales- han salido largamente del cauce reservado a la protección de los derechos subjetivos del sujeto innovador -que constituyó su primigenia razón de ser- para convertirse en un derecho vinculado con el acceso al mercado y con la política económica y científica de las naciones. Como muy bien lo ha señalado Francisco Ost, la patente más que una propiedad estática concedida a un inversor individual pasaría a ser un instrumento dinámico de acceso y control del mercado en beneficio de empresas industriales que dispongan de los capitales suficientes para controlar la marcha de la investigación y los mercados creados por los productos y procedimientos, que permite comercializar esta investigación (OST, 1996, p. 70).

La emergencia de la Big Science ha apartado de la escena al sujeto innovador, el que ha sido reemplazado por empresas que cuentan con equipos de investigadores que desarrollan su actividad en grandes laboratorios, con costosas instalaciones e instrumentales que requieren de ingentes inversiones. 
El panorama que hoy presenta el derecho de la propiedad industrial, en este campo - que dicho sea de paso afronta una aguda crisis- presenta algunas notas que es preciso destacar (BARTON, 1933):

a) la tendencia a comprender bajo su dominio la totalidad de la materia viva, la materia biológica y la información genética (genes, microorganismos, plantas, partes de seres vivos, organismos complejos, etc.) así como a los procesos biológicos ${ }^{8}$;

b) la ruptura de la distinción entre el descubrimiento (excluido tradicionalmente de su régimen) y el invento (en principio, patentable). La Directiva Europea 98/44C sobre Protección de las Innovaciones Biotecnológicas nos da un claro ejemplo de ello al disponer que la materia biológica aislada de su entorno natural puede ser objeto de una invención, aún cuando ya exista anteriormente en su estado natural (art. 3.1) ;

c) la extensión de la protección conferida por la patente a un producto que contenga o consista en información genética, a toda materia en la que se incorpore el producto y en la que se contenga y ejerza su función la información genética (art. 9 de la Directiva). La amplitud de las reivindicaciones de una patente es un elemento fundamental para determinar el grado de control que su titular podrá ejercer sobre las invenciones posteriores. Cuanto más amplia es la patente original, mayor es la posibilidad que nuevas invenciones en áreas próximas relacionadas sean consideradas como infractoras (CORREA, 2005, p. 57);

d) la extensión de la protección de una patente relativa a materia biológica, a cualquier materia biológica obtenida a partir de dicha materia biológica por reproducción o multiplicación en forma idéntica o diferenciada y que posea las mismas propiedades, con lo que se extiende el monopolio a generaciones futuras (art. 8.1 de la Directiva);

\footnotetext{
${ }^{8}$ La Directiva Europea 98/44/C admite el patentamiento de genes o secuencias de genes, aún cuando contengan la misma información natural (art. 5.2). En torno a los procesos biológicos la Convención de la Patente Europea (CPU) excluye en su artículo 53 de la protección patentaria a los procedimientos esencialmente biológicos para la obtención de plantas y animales. No obstante ello, la Oficina Europea de Patentes ha desarrollado una tendencia aperturista que culminó con la decisión en la causa "Plantas híbridas Lubridizol" del 10-11-88 en la que estableció que el carácter relevante de la contribución técnica para determinar la existencia de un producto esencialmente biológico debería ser aplicada en función de la influencia de aquél sobre el resultado obtenido (T320/87, página 77).

${ }^{9}$ La distinción fundamental entre descubrimiento, teoría científica, etc. -a priori excluidas como tales de la patentabilidad- e innovaciones aplicativas (patentables) se justifica sobre todo por la defensa del modo de producción de la investigación pura. Es justo recordar que la ciencia se nutre de intercambios, opciones, puesta en común de saberes, de verificación en "comunidad”; si bien a veces en viva contraposición personal entre los investigadores, de nuevas hipótesis enfrentadas y que, el tradicional modo de producción, "no propietario" es también el más eficiente para el desarrollo de la investigación pura. No es este un axioma ideológico sino más bien el fruto de una larga reflexión desarrollada sobre la base de la experiencia, ya sea de economistas de la escuela liberal, ya de estudiosos de la historia de la propiedad intelectual. Si la investigación pura fuese "atraída" hacia el ámbito de la lógica propietaria de la investigación aplicada se reducirían las potencialidades innovadoras, así como según advierte Rebeca Eisenberg, los mismos espacios de libertad (GHIDINI, 2002, p. 24).
} 
e) la concesión de patentes con reivindicaciones amplias, genéricas y funcionales que desorbitan el real aporte hecho al estado de la técnica por el solicitante ${ }^{10}$;

f) el requisito de "utilidad" exigido por la ley norteamericana en lugar de la "aplicación industrial" justifica el otorgamiento de patentes que en realidad son meras herramientas de investigación, al solo efecto de asegurar la reserva del mercado ${ }^{11}$;

g) una tendencia general no disimulada hacia el patentamiento irrestricto de las "innovaciones biotecnológicas" -expresión abierta que envuelve cualquier aprovechamiento actual o potencial de materia viva o sus productos- evidenciada en leyes, resoluciones administrativas y sentencias judiciales. Sobre este particular Tallacchini destaca que en la cadena de sentencias que ha conducido a la patentabilidad de las biotecnologías, elementos científicos y jurídicos se mezclan con el fin de producir una única evidencia: la total legitimidad de la nueva industria biotecnológica, avalada al unísono por la verdad de la ciencia y por la conformidad de derecho (TALLACCHINI, 2003, p. 115);

h) el paulatino desgaste del derecho de las obtenciones vegetales -que más allá de las críticas que genera- implica un sistema de protección más abierto que el de las patentes. El Acta de 1991 del Convenio UPOV nos da una muestra clara de esta tendencia.

\section{LOS EFECTOS DE LAS POLÍTICAS DE PATENTAMIENTO SOBRE LOS PAÍSES SUBDESARROLLADOS}

El Acuerdo TRIPS del GATT que hoy se erige como pieza clave en la estructura de los derechos intelectuales a nivel mundial, fue resistido por los países subdesarrollados, en tanto consideraron que el régimen allí establecido era negativo a sus intereses.

No obstante ello, cabe señalar que con el fin de evitar un desequilibrio pronunciado el Acuerdo estableció en su artículo 7 -ubicado en las disposiciones generales y principios básicos- que la protección y la observancia de los derechos de propiedad industrial

\footnotetext{
${ }^{10}$ Según la doctrina americana las reivindicaciones amplias pueden cubrir realizaciones inútiles (inoperantes) toda vez que el hecho que las reivindicaciones puedan englobar realizaciones inoperantes "no es un motivo determinante de nulidad” (Elli Lilly versus Genetic Drug Sales 174 USPQ, 65, 5 Circuito, 1972). Además del alcance "horizontal" de las patentes sobre variedades de plantas y especies, que puede desplazar el germoplasma público hacia el ámbito de la propiedad privada protegida, también resulta problemático el "alcance vertical” en la producción de rasgos mejorados. En efecto, la protección puede remontarse al germoplasma no mejorado contenido en los individuos emparentados con un cultivo patentado. Este alcance vertical a través de generaciones plantea una situación difícil, puesto que las partes no descriptas con anterioridad de líneas de propiedad pública pueden de esta manera quedar incluidas dentro de la categoría de propiedad privada. Muchos obtentores e investigadores que operan en el ámbito público comparten esta preocupación y temen que las patentes relativas a cultivares comerciales se remonten a líneas progenitoras e incluso al germoplasma no mejorado (Stilles, W.: cit., por Correa, Carlos: Derechos de soberanía y de propiedad intelectual sobre los recursos genéticos, en “Redes”, vol. 4 N² 2, Buenos Aires, Septiembre 1995, pág. 29).

${ }^{11}$ Conforme a la ley norteamericana es posible patentar un hallazgo que si bien a ese momento no presenta una concreta aplicación industrial, puede servir para hallarla en un momento posterior, con lo cual se bloquean líneas enteras de investigación y se establece una reserva de mercado, sin sustento suficiente.
} 
debía contribuir a la promoción de la innovación tecnológica y a la transferencia y difusión de la tecnología, en beneficio recíproco de los productores y de los usuarios de conocimientos tecnológicos y de modo que favorezcan el bienestar social y económico y el equilibrio en los derechos y obligaciones.

Comentando este artículo, a poco de la firma del Acuerdo, señalábamos que los países industrializados deberían considerar que los instrumentos gestados en los acuerdos del GATT no pueden constituir medidas dirigidas a acrecentar la brecha tecnológica que separaba a los estados miembros, sino sólo instrumentos orientados a facilitar el comercio en un mundo interdependiente (BERGEL, 1997, p. 66).

A diez años de su firma debemos expresar nuestro desaliento y nuestro pesimismo por el funcionamiento del sistema que se instituyó, visto desde la órbita de los países subdesarrollados.

Tal como lo destaca Días Varella, el Acuerdo TRIPS no benefició a los países del Sur, ya que éstos no producen tecnología. En un contexto de expansión de desigualdades internacionales, las normas de protección intelectual no estimulan la innovación tecnológica en el Sur; por el contrario, ellas aumentan la dependencia tecnológica y el flujo financiero del Sur para el Norte (VARELLA, 2004, p. 185).

En esta misma dirección, Sachs destaca que el 15\% de la población de la tierra posee casi todas las innovaciones tecnológicas; otra parte que quizá comprenda la mitad de la población mundial tiene capacidad para adaptar esas tecnologías en la producción y en el consumo; y el resto, que abarca alrededor de un tercio de la población mundial, está tecnológicamente aislada, sin capacidad de adaptar nuevas tecnologías extranjeras y mucho menos para innovar por su cuenta (SACHS).

Esto nos habla muy a las claras del fracaso del sistema, que lejos de cumplir con los objetivos enunciados, ha contribuido a acrecentar la brecha entre los países desarrollados y los subdesarrollados.

El acuerdo TRIPS no implicó ganancias mutuas sino que situó a la OMC principalmente en una posición recaudadora de las rentas procedentes de la propiedad intelectual en nombre de las corporaciones multinacionales. Ello da una mala imagen de la OMC y la opinión de muchos -especialmente de las organizaciones no-gubernamentalesdemuestra cómo la OMC ha sido “capturada” por las corporaciones multinacionales (BHAGWATI, 2005, p. 385). 
En una línea coincidente el informe de la Comisión sobre Derechos de Propiedad Intelectual, señala: “de nuestro análisis se deduce que la mejor forma de velar por los intereses de los países en desarrollo consiste en adaptar su sistema de propiedad intelectual a sus propias circunstancias económicas y sociales” (BHAGWATI, 2005, p. 375).

En esta dirección cabe recordar que la USTPO ha implementado un plan a cinco años vista denominado 21st century plan a fin de armonizar normas sobre propiedad intelectual con Europa y Japón.

Es interesante destacar que en el plan se expresa "trabajaremos tanto a nivel bilateral como multilateral con nuestros socios para crear un modelo de protección de la propiedad intelectual a través del mundo”.

De la redacción del documento surge con toda claridad que los “socios” son Europa y Japón, que integran la triade que hoy gobierna a nivel mundial la materia.

Los países subdesarrollados no sólo que quedan excluidos de los planes sino que a la postre devendrán “sujetos pasivos” de los acuerdos que se logren en beneficio de los países industrializados.

Todo parece indicar que desde los años ochenta los países esencialmente importadores de tecnología perdieron la iniciativa de formular alternativas de crecimiento tecnológico endógeno en este campo, adecuadas a sus necesidades de desarrollo (DE LEÓN, 2004).

Ante este panorama, abrir el campo del patentamiento al extremo que exceda los parámetros clásicamente aceptados puede importar el otorgamiento de ventajas competitivas sin una correlativa transferencia de tecnología por parte de los países industrializados y sin el reconocimiento de derechos otorgados por otros instrumentos jurídicos (vgr. la CBD en lo relativo al reconocimiento de la soberanía de los estados sobre sus recursos genéticos y la protección de los conocimientos tradicionales asociados), que podría contribuir al logro de una mayor equidad en el orden internacional.

No se trata de adaptarse a las necesidades del mercado o a los retos de las nuevas tecnologías, como podría deducirse de un primer análisis superficial y engañoso. Si estamos hablando de políticas macroeconómicas -la propiedad industrial juega un rol importante en estas políticas- hay que tomar en cuenta el riesgo de otorgar beneficios sin una contrapartida fundada en criterios de equidad y justicia. 


\section{EL CONFLICTO ENTRE LOS DERECHOS DE PROPIEDAD INDUSTRIAL Y LOS RECURSOS GENÉTICOS.}

Un tema central para los países megadiversos, que en su inmensa mayoría son subdesarrollados, se relaciona con la protección y aprovechamiento de sus recursos genéticos y los conocimientos y prácticas tradicionales vinculados a los mismos, tema que debe ser considerado en el contexto de los derechos de propiedad intelectual.

El artículo 10 de la CDB establece que se entiende por material genético a "todo material de origen vegetal, animal, microbiano o de otro tipo que contenga unidades funcionales de la herencia”; y el artículo 15 a su vez señala que "se entiende por recursos genéticos el material genético de valor real o potencial”12.

El advenimiento de la nueva tecnología particularmente la basada en técnicas de ADN recombinante (ingeniería genética), ha valorizado el material genético ya que se ha constituido en la materia prima de una industria en plena expansión: la biotecnológica.

A juicio de Caillaux Zazzali, cualquier debate de la interrelación entre diversidad biológica y los derechos de propiedad intelectual debe incluir no sólo los posibles efectos de los derechos de propiedad sobre formas de vida y sobre invenciones derivadas de la investigación y uso de los recursos genéticos, sino también entre otros aspectos de importancia:

a) los mecanismos para controlar eventuales abusos de posición dominante en los mercados, generada a partir de los monopolios legales que nacen de la concesión de derechos de la propiedad intelectual;

b) el análisis de los sistemas sui géneris de protección de "invenciones" e "innovaciones" derivadas de la investigación y del uso de recursos genéticos;

c) la cuestión del acceso y la transformación de tecnologías que utilizan recursos genéticos debidamente protegidos por patentes y otros derechos de propiedad intelectual;

d) su relación con el desarrollo sostenible en las necesidades de salud y alimentación de la población (CAILLAUX, 1997, p. 89).

\footnotetext{
12 Daniel Querol caracteriza a los recursos genéticos como la variedad genética almacenada en los cromosomas y en otras estructuras conteniendo ADN (moléculas que conforman los genes) que codifican el desarrollo de cadenas de polipéptidos (proteínas). Estos polipéptidos determinan el funcionamiento de los organismos vivos en el que se encuentra, tanto en sus funciones básicas (respiración, fotosíntesis y absorción de nutrientes en el caso de las plantas) como en características específicas como sabor, resistencia a plagas y enfermedades, etc. (Recursos genéticos: nuestro tesoro olvidado, edit. Industrial Gráfica, Lima 1988, pág. 2).
} 
Aquí se da la paradójica situación que los países con mayor desarrollo científicotecnológico pertenecen al Norte y carecen de recursos genéticos mientras que los países subdesarrollos del Sur que carecen de una estructura científico-tecnológica adecuada a sus necesidades, son ricos en recursos genéticos.

Este desbalance motivó que la Convención sobre Diversidad Biológica (CDB Río 1992) tratara de buscar una solución equitativa. En lo referente a los recursos genéticos, el art. 15 establece el principio general -atento al reconocimiento de la soberanía de los estados sobre los recursos naturales ubicados en su territorio- que otorga la facultad de regular el acceso a los recursos genéticos, los que quedan sometidos a las respectivas legislaciones nacionales.

El sistema que instituye la CDB, sobre este particular, se completa con:

a) el compromiso de cada parte contratante de asegurar y/o facilitar a las otras partes el acceso a tecnologías pertinentes para la conservación y utilización sustentable de la diversidad biológica o que utilicen recursos genéticos, así como la de transferir esas tecnologías (artículo 16.1);

b) el acceso de los países en desarrollo a esas tecnologías, lo que se asegurará o facilitará en condiciones justas y en términos más favorables (artículo 16.2);

c) la adopción de medidas legislativas, administrativas o de política por los países contratantes para asegurar la participación efectiva de los países subdesarrollados en las actividades de investigación sobre biotecnología de los otros países, en particular de los que aporten recursos genéticos para tales investigaciones (artículo 19.1);

d) la adopción de medidas particulares para promover e impulsar en condiciones justas y equitativas el acceso prioritario de los países contratantes, en particular de los países en desarrollo, a los resultados y beneficios derivados de las biotecnologías basadas en recursos genéticos aportados por las partes contratantes (artículo 19.2).

El referido artículo 7 del Acuerdo TRIPS trata de balancear los avances registrados en la protección de la propiedad industrial con acceso a la tecnología por parte de los países subdesarrollados.

A la luz de estos textos pareciera que los objetivos de ambos instrumentos son coincidentes en lo que concierne al acceso a los recursos genéticos y a la transferencia de tecnología vinculada con los mismos, mas en los hechos existen puntos de controversia que colocan a los países del Sur ricos en biodiversidad en una posición desventajosa.

Los países industrializados no sólo establecieron monopolios -vía patente- en 
base muchas veces a cuestionables inventos, sino que forzando el sistema legal ampliaron su dominio a simples descubrimientos, lo que permitió y permite apropiarse de la información genética, de microorganismos, plantas y animales. Sobre este particular cabe señalar que tras el Acuerdo de la CDB en 1992 y en base al mismo avanzó el proceso de transición del Compromiso Internacional sobre Recursos Fitogenéticos de la FAO hacia un tratado (Tratado Internacional de las Plantas y los Recursos Genéticos para la Alimentación y la Agricultura) (ITPGRFA) que se suscribió en el 2001. El mismo tiene el objeto específico de facilitar para el bien común el acceso a los recursos fitogenéticos de las partes contratantes y aquellos conservados en colecciones internacionales, reconociendo que éstos constituyen una materia pura indispensable para el fitomejoramiento de los cultivos y que numerosos países dependen de los recursos genéticos que se originan en estos países. Representa una aplicación de los principios de la CDB a las características específicas de los recursos filogenéticos (PROPIEDAD INTELECTUAL Y POLÍTICAS DE DESARROLLO, 2005, p. 190).

Tanto el Acuerdo TRIPS como la CDB se refieren a la protección de la propiedad intelectual. Si bien el primer instrumento es específico sobre el tema, el segundo contiene diversas menciones sobre patentes lo que nos muestra dos instrumentos internacionales relacionados en cuya implementación se presentan áreas conflictivas que es necesario aclarar a fin de que cada uno de los referidos instrumentos pueda cumplir con los objetivos propuestos en los enunciados, sin entrar en colisión.

Tres temas se presentan como centrales en el análisis de los puntos en conflicto: participación en los beneficios derivados de las tecnologías; acceso apropiado y transferencia de tecnología y por último protección de las comunidades indígenas y de los conocimientos tradicionales vinculados con la conservación de la biodiversidad. 


\section{Pasamos a su desarrollo:}

\section{A) Participación en los beneficios ${ }^{13}$ :}

Frente al artículo 15.7 y otras disposiciones de la CDB que invitan a una participación justa y equitativa de los beneficios derivados de las tecnologías y de los conocimientos de los integrantes de las comunidades locales e indígenas, el Acuerdo TRIP's confiere al titular de la patente (sea de producto o de procedimiento) derechos exclusivos que impiden sin su consentimiento la fabricación, uso, venta, oferta para la venta, importación para esos fines del producto objeto de la patente u obtenido del procedimiento patentado (artículo 28).

Si las patentes se obtienen en base a recursos genéticos originados en un Estado al que la Convención le ha reconocido soberanía sobre los mismos (artículo $15.1 \mathrm{CDB}$ ) o en base a conocimientos suministrados por las comunidades indígenas o locales, el conflicto queda al descubierto.

El respeto a la soberanía de los países signatarios de la CDB sobre sus recursos genéticos, así como sobre los conocimientos y prácticas tradicionales de las comunidades indígenas o locales, cuando se trata de reconocer DPI, es imprescindible para mantener el equilibrio buscado.

En caso contrario, los reconocimientos que hace la CDB se convierten en simples principios declamatorios. Por ello se impone que los beneficios derivados de patentes que utilicen recursos genéticos o conocimientos de comunidades locales sean equitativamente compartidos con el país de origen de tales recursos o conocimientos (PÉREZ SALOM , 2002, p. 206).

Cuando se trata de patentes que incorporen recursos genéticos o conocimientos primitivos debería expresarse en el título el país de origen de tales recursos o conocimientos y verificar si el peticionante ha cumplido con las disposiciones internas de cada país para la obtención del recurso o del conocimiento primitivo asociado.

Esto, si bien ha sido objeto de algunas regulaciones aisladas en los países subdesarrollados, debería ser incorporado al Acuerdo TRIP's a fin de que la norma del referido artículo 28 no invalide en la práctica los derechos que emanan de la CDB.

\footnotetext{
${ }^{13}$ No existe una definición oficial con relación a los beneficios generados por el uso de los recursos genéticos; pese a ello las guías de buena conducta de Bonn, el Tratado Internacional de la FAO y otros documentos han esbozado, a través de su articulado las directivas sobre las modalidades de beneficios. Las guías de buena conducta de Bonn sugieren que sean considerados los beneficios a corto, mediano y largo plazo y que los términos mutuamente acordados cubran las condiciones, obligaciones, procedimientos, los tipos, la época de distribución y los mecanismos de beneficio a ser repartido. Los beneficios monetarios deben incluir: costos para el acceso, pagos anticipados, pagos de prestaciones, pago de regalías, fondos de depósitos, salarios, fondos de investigación y joint-ventures. Los beneficios no monetarios pueden comprender: reparto de los resultados de investigación y desarrollo, colaboración y contribución a los programas de investigación y desarrollo científico; participación en el desarrollo de producto, colaboración, cooperación y contribución a la educación; y entrenamiento, acceso a las instalaciones ex situ de los recursos genéticos y a las bases de datos, transferencia de conocimiento y tecnología al proveedor de los recursos genéticos, capacitación, acceso e información científica, contribuciones a la economía local, beneficios de seguridad de alimentación y subsistencia, reconocimiento social, posesión conjunta de derechos de propiedad intelectual relevantes, etc (KUCHIRO, 2004, p. 206).
} 


\section{B) Acceso apropiado y transferencia de tecnologías relevantes:}

La CDB establece en su artículo 16, inciso 1, que tanto el acceso a la tecnología como la transferencia entre partes contratantes son elementos esenciales para el logro de los objetivos del convenio y que cada parte se compromete a asegurar y/o facilitar a las otras partes contratantes el acceso a tecnologías pertinentes para la conservación y utilización sostenible de la diversidad biológica o que utilicen recursos genéticos, así como a la transferencia de esas tecnologías.

El inciso $5^{\circ}$ contiene una disposición muy importante para orientar las relaciones entre ambos instrumentos: "las partes reconociendo que las patentes y otros derechos de la propiedad industrial pueden influir en la aplicación del convenio, cooperarán a este respecto de conformidad con la legislación nacional y el derecho internacional para velar porque esos derechos apoyen y no se opongan a los objetivos del convenio.”

Más allá de una formal coincidencia cabe reconocer algunos puntos de discordia en la aplicación de ambos instrumentos ${ }^{14}$.

Al margen de declaraciones grandilocuentes queda por demostrar si el sistema de propiedad industrial acuñado por el Acuerdo TRIP's promueve la transferencia de tecnología, ya que los derechos exclusivos otorgados a favor de los titulares de patentes pueden, en ciertos casos, limitar a los eventuales usuarios, en especial de los países en desarrollo, el acceso a la tecnología en términos favorables y justos ${ }^{15}$.

En este punto cabe destacar algunos temas en particular que necesitan de una mayor y mejor elaboración.

En primer lugar, el relativo a la extensión de los derechos otorgados por patentes. Es sabido que el derecho acordado por la patente implica en los hechos investir a su titular de un "ius excluendi" que permite excluir a terceros de la explotación del producto o del procedimiento protegido.

Si la patente incluye como reivindicación a un ser vivo (v.gr. un organismo no modificado genéticamente), un gen o una secuencia de un gen referidos a recursos genéticos originarios del país, el titular gozará de ese derecho de exclusión lo cual evidentemente entra en colisión con los derechos de soberanía que el referido artículo 15 de la CDB reconoce al Estado.

En materia vegetal los llamados derechos del obtentor importan una particular forma de protección de las variedades que no necesariamente colisionan con el reconocimiento de la soberanía de los Estados sobre sus recursos genéticos, ya que no protegen el germoplasma como tal.

Este sistema no otorga derechos exclusivos sobre genes, los que de esta forma permanecen en el dominio público para actividades de investigación y de mejoramiento vegetal.

Desde otro extremo podría darse el caso que el otorgamiento de licencias obligatorias para aumentar el nivel de transferencia de tecnología relevante para la conservación de la diversidad biológica pueda ser cuestionado conforme a las previsiones del Acuerdo TRIP's.

El artículo 27 3b) del Acuerdo TRIP’s estableció que los países firmantes deberían asegurar la protección de las variedades vegetales por patentes, o por un sistema sui-géneris (sin mencionar

\footnotetext{
${ }^{14}$ UNCTAD: Intelectual property rights. Implications for development, Geneve 2003, pág. 85 y siguientes.

${ }^{15}$ Ver sobre este particular: Lesser, W.: Sustainable use of genetic resources and the reconvention on biological diversity, CAB International, New York 1998, pág. 162 y siguientes.
} 
específicamente el de obtentores vegetales), agregando que esta norma debería ser revisada en un período de 4 años.

Pese a que transcurrió en exceso el período de revisión, aún no se cumplió con el mandato. En tanto aumentó la presión por una protección más amplia de las obtenciones vegetales (sistema UPOV 91, que acorta la distancia con las patentes; o simplemente proteger por patentes en todos los casos).

La revisión del artículo 27 3b) debería preservar el derecho de los países a sus conocimientos sobre plantas y animales, incluidos los genes y las plantas y animales genéticamente modificados, y al mismo tiempo facilitar a los países la creación de sistemas sui géneris para la protección de las obtenciones vegetales que sean idóneas para sus sistemas agrícolas. Dichos sistemas deben orientarse a permitir el acceso a las obtenciones protegidas para poder seguir realizando investigaciones y crear nuevas variedades, además de proporcionar a los agricultores el derecho de guardar y volver a usar las semillas, incluida la posibilidad de intercambio y la venta informal de las mismas (PROPIEDAD INTELECTUAL Y POLÍTICAS DE DESARROLLO, 2005, p. 188).

\section{C) Protección de los conocimientos, innovaciones y prácticas indígenas ${ }^{16}$ :}

Uno de los aspectos destacados de la CDB fue el reconocimiento de las innovaciones y de las prácticas de las comunidades indígenas y locales que entrañan estilos tradicionales de vida pertinentes para la conservación y la utilización sostenible de la diversidad biológica así como la promoción de su aplicación más amplia con la aprobación y participación de quienes posean conocimientos, innovaciones y prácticas; fomentando que los beneficios derivados de la utilización de esos conocimientos, innovaciones y prácticas se compartan equitativamente (artículo 8, inc. j).

Esos conocimientos y prácticas proveen de una importante fuente de información para el manejo sostenible de la diversidad biológica en beneficio de la humanidad y constituyen, al mismo tiempo, un importante atractivo para las empresas agroquímicas y farmacéuticas, en tanto su aprovechamiento puede importar beneficios económicos relevantes.

No obstante ello, no se los ha considerado como merecedores de protección legal, que recompense a las comunidades. Los conocimientos y prácticas tradicionales han prestado y prestan relevantes servicios a la conservación de la diversidad biológica y al desarrollo de la biotecnología industrial, posibilitando la utilización de plantas en la industria (especialmente la farmacéutica).

Se los ha considerado siempre como una especie de patrimonio común, como una fuente de la cual pueda abrevar quien se acerque sin contraprestación alguna, relegándolos a la categoría de conocimientos primitivos, carentes de valor científico y económico.

Vandana Shiva (2003, p. 52) observa que al transformarse la pluralidad de conocimientos en una jerarquía de conocimientos, el ordenamiento horizontal de sistemas diferentes pero igualmente válidos y diversos se convierte en un ordenamiento vertical de sistemas desiguales, imponiéndose los cimientos epistemológicos del sistema a los otros, para invalidarlos. Después, esta transformación de las variedades de conocimientos en jerarquías de conocimientos se utiliza para reivindicar los actos de interpretación como actos de invención. La interpretación se mal interpreta y se denomina "creación" de conocimiento. De esta manera un cambio sociológico se trata falazmente como cambio epistemológico.

\footnotetext{
${ }^{16}$ Los conocimientos son un componente intangible e inmaterial. Las innovaciones constituirían por el contrario los productos materiales que manifiestan (de mayor o menor grado) los conocimientos antes mencionados. Por último las prácticas constituyen procedimientos y procesos que las comunidades han ideado y repiten para la obtención de determinados productos (RUIZ, 2002, p. 90).
} 
Esta razón justifica la necesidad de protegerlos en forma adecuada. Adelantamos que no es tarea fácil la búsqueda de vías de protección.

Mientras el sistema de los TRIP’s apunta a la protección de los conocimientos formales, los conocimientos a los que se refiere al artículo 8 inc. j) son conocimientos informales ${ }^{17}$.

Este carácter informal que lo diferencia de los que tradicionalmente protegen los DPI tiene varias características:

a) de común es un conocimiento colectivo y no individual. Es compartido por un número indefinido de sujetos que conforman una comunidad. El punto no es la creación colectiva per se, sino cómo esta creación se defiende, transmite y mantiene al interior de la comunidad y cómo esta misma creación se vincula y se articula con el mundo exterior a la comunidad (RUIZ, 2002. p. 87);

b) es intergeneracional, transmitido y transmisible por tradición oral a través del tiempo ${ }^{18}$;

c) no es novedoso, si apuntamos al concepto de novedad que informan los DPI.

Esto nos aparta de la aplicación de un sistema tradicional de DPI para su protección.

A ello debemos adicionar una circunstancia económica que se convierte en un obstáculo difícil de superar. Los DPI necesitan tanto para su obtención como para su conservación de un considerable aporte de dinero del cual no disponen las referidas comunidades (tasas, honorarios de técnicos, servicios anuales, etc.).

De todas formas esto no puede convertirse en un obstáculo insalvable que juegue en contra de los reales titulares de estos derechos y que en función de ello los someta permanentemente al escamoteo o a la apropiación de los recursos tangibles o intangibles sin contraprestación alguna.

\footnotetext{
${ }^{17}$ Astudillo Gómez, F.: Derechos de propiedad industrial de las comunidades indígenas sobre los conocimientos tradicionales asociados a los recursos biológicos. ULA: Revista anual de propiedad intelectual, año III $\mathrm{N}^{\circ} 4$ y 5 , Mérida 2000, pág. 227. Correa, C.: Protección de la propiedad industrial de los conocimientos tradicionales relativos a recursos genéticos vegetales, Seminario internacional sobre conocimientos tradicionales y recursos genéticos, INDECOPI, Lima 1992, pág. 2.

${ }^{18} \mathrm{La}$ India ha solicitado en diversos foros la formación de bases sobre conocimientos tradicionales y ya comenzó a desarrollar una biblioteca digital de conocimiento tradicional (TKDL), un banco de datos en el que se puede indagar la información ya documentada relacionada con los conocimientos tradicionales en salud y plantas medicinales usados por profesionales.
} 
Una vía de salida consistiría en implementar una forma de protección adecuada a la realidad. Los aspectos técnicos pueden ser superados si existe la decisión política de reconocer tales derechos.

En materia de biotecnología tenemos el ejemplo de las obtenciones vegetales que en definitiva cuentan con una protección sui-generis que se aparta de los derechos de patentes y que no ha sido objeto de mayores cuestionamientos.

La armonización de las normas del Acuerdo TRIP’s con las de la CDB impone la consagración de una nueva categoría de derechos sui-generis que partan de inventariar en cada comunidad las prácticas y los conocimientos asociados.

Existen varios casos en que se ha verificado una apropiación abusiva de conocimientos y prácticas tradicionales de las comunidades locales con el fin de obtener patentes de invención (caso de la ayahuasca, del frijol mexicano, de la uña de gato, etc.).

Para evitar estos efectos negativos, la India ha propuesto que en una futura reforma del art. 27.3b del TRIP's se requiera al solicitante de la patente aclarar la fuente de origen del conocimiento tradicional usado para obtener el material y la prueba del conocimiento informado y de los beneficios compartidos respecto del material biológico ${ }^{19}$.

Igualmente propuso que el art. 29 sea clarificado o modificado para asegurar que el solicitante revele el conocimiento y el material biológico y garantice que las leyes y prácticas del país de origen hayan sido suficientemente respetadas (Encuentro del Consejo TRIPS's, octubre de 2000).

\section{CONCLUSIONES}

Al tiempo de concluir con estas reflexiones resulta importante visualizar qué tipo de intereses se deben privilegiar en un sistema de propiedad industrial. No siempre los intereses sectoriales coinciden con los generales de la sociedad y naturalmente, cuando esto ocurre, debemos privilegiar los generales en tanto los derechos de propiedad industrial son un instrumento de primer orden en la implementación de las políticas económicas de los países.

\footnotetext{
${ }^{19}$ La propuesta pretende ayudar a realizar una repartición justa y equitativa de los beneficios reclamados por la Convención de Biodiversidad. Se propone asegurar que los recursos y conocimientos tradicionales hayan sido adquiridos de acuerdo con las normas de acceso a la biodiversidad y respetando los beneficios de los países fuente (DUTFIELD, 2004, p. 57)
} 
Muchos de los falsos derechos de propiedad industrial -se ha señalado- pueden encubrir un alto costo social, comprometiendo el código de valores de la competitividad.

Los países subdesarrollados -entre los que incluyo a los de la región- hace tiempo que vienen librando una batalla sin cuartel con los países industrializados, precisamente para evitar que mediante una acrecentamiento de los derechos de propiedad industrial se ensanche aún más la brecha tecnológica y científica que los separa, ahogando las posibilidades de un desarrollo económico sostenible.

Esta lucha no puede ser desconocida por quienes invocan intereses sectoriales comprendida la biotecnología- por lo que todo intento de ampliar las concesiones en este campo debe ser acompañado de un estudio de su impacto en la sociedad.

No resulta atendible sostener una política esquizofrénica en el patentamiento biotecnológico que -por un lado- apunte a defendernos de los continuos embates de los países industrializados para poner el sistema de los derechos de propiedad industrial a su servicio y por otro lado- abra la compuerta al patentamiento amplio en el campo de la biotecnología, respondiendo a los requerimientos del mercado.

Cada vez que un país subdesarrollado cedió terreno en el área de los derechos intelectuales (por vía de acuerdos bilaterales de libre comercio, de acuerdos de inversiones o simplemente aceptando imposiciones de los países industrializados), no sólo se afectaron los intereses generales de la comunidad nacional, sino que -paralelamente- se debilitó el accionar de los demás países subdesarrollados en su lucha por un sistema más justo y equitativo a nivel global.

Mucho es lo que los países subdesarrollados tienen que perder en el caso de acceder a los requerimientos de la industria biotecnológica, en la medida que impulse un sistema más flexible y abierto.

Hemos señalado más arriba -con base en cifras incontestables- que las patentes son mayoritariamente concedidas en países extranjeros, los que obtienen los mayores beneficios del sistema de propiedad industrial.

Lo que estamos refiriendo no implica sustentar una posición contraria al progreso de la biotecnología ni desconocer que esta puede constituir una gran esperanza para la región contribuyendo decididamente al desarrollo económico. Pero cabe señalar que la promoción o estímulo de esta actividad debe centrarse en otros instrumentos legales (leyes de promoción, incentivos fiscales, etc.). 
Otro aspecto que debe ser sopesado debidamente a la hora de optar por un sistema abierto de propiedad industrial en el campo de la biotecnología es el de la relación existente entre la investigación básica y la aplicación industrial.

El patentamiento de reales aportes de la ciencia básica -como está sucediendo en la actualidad- no sólo que entorpece la investigación científica al bloquearla aguas abajo, sino que constituye una traba a la libre circulación del conocimiento.

Abrir un campo permisivo en el patentamiento de biotecnología, so pretexto que esta actividad necesita de mayores aportes de inversión, implica un claro desconocimiento de las bases y de los fundamentos de la propiedad industrial.

No es función del derecho de la propiedad industrial la de proteger inversiones -o al menos no es su función primigenia- ya que deben otorgarse los privilegios de exclusiva a quien aporte a la sociedad una invención novedosa, útil industrialmente y que evidencie una actividad inventiva superadora del estado de la técnica.

La patente -según lo enseña Remiche (2004, p. 75)- no es nada más que una incitación entre otras para la innovación y sin querer minimizar su influencia es preciso colocarla en su justo lugar al lado de otros institutos que desempeñan un papel considerable en la política de innovación. Existe un abanico importante de apoyos directos o indirectos a la investigación y al desarrollo que lleva a la innovación, sin olvidar la concurrencia y la necesidad de la empresa de conquistar y mantener continuamente sus mercados.

La necesaria armonización entre la función de la patente como estímulo a la investigación y a la innovación, por una parte, y los intereses generales de la sociedad, traducidos en la libre circulación del conocimiento y en la libre competencia sólo puede darse en un sistema de propiedad intelectual estructurados sobre bases racionales que tenga como meta no la satisfacción de intereses sectoriales sino la del interés común. Desde esta órbita coincidimos con Chauveau (2004, p. 123) en cuanto sostiene que no parece que el refuerzo de la patente se pueda justificar más que si ello implica un aporte para la mejora del bienestar general.

En síntesis consideramos que un sistema de propiedad industrial que respete lealmente los principios básicos de la materia puede otorgar a los industriales un instrumento valioso para proteger la innovación en el campo de la biotecnología, sin que sea necesario ni conveniente otorgar concesiones que a la postre afecten la investigación científica, la libre circulación del conocimiento y la competencia. 
La construcción de un sistema de patentes que equilibre los diferentes intereses en juego -se ha señalado- deberá ser una solución política es decir resultar de una voluntad colectiva. No se trata de satisfacer intereses sectoriales tal como si la propiedad industrial fuese un derecho propio de un sector en particular. La relevancia que asume las normas regulatorias en diversos grados de la actividad (económica, científica, social) justifica y obliga a un examen desapasionado de los problemas que se presentan a fin de privilegiar en mejor forma los intereses generales (REMICHE, 2004, p. 75).

\section{REFERÊNCIAS}

BARTON, J. H. Reforming the patent system, Science, n. 287, 1933.

BERGEL, S. D. Disposiciones generales y principios básicos del Acuerdo TRIPS. In: Propiedad intelectual en el GATT. Temas de derecho industrial y de la competencia, edit. Ciudad Argentina, Buenos Aires 1997.

BHAGWATI, J. Temas de derecho industrial de la competencia: propiedad intelectual y políticas de desarrollo. Buenos Aires: Ciudad Argentina, 2005.

CAILlAUX, Zazzali, J. Propiedad intelectual, diversidad biológica y conocimientos tradicionales: una visión desde los Andes y la Amazonia. edit. Buenos Aires: Ciudad Argentina, 1997. (Temas de Derecho Industrial y de la Competencia, n. 2).

CHAUVEAU, S. Marchandisation et brevet. In : Vivant, M. (Org.). Propiété intellectuelle et mondialization. París: Dalloz, 2004.

CORREA, C. Aperfeiçoando a eficiencia económica e a equidade pelo creaçao de leis de propiedade intelectual. In: VARELLA, M. Días. (Org.). Propiedade intelectual $e$ desenvolvimento. São Paulo: Lex, 2005.

CORREA, Carlos. Derechos de soberanía y de propiedad intelectual sobre los recursos genéticos. Redes, Buenos Aires, v. 4, n. 2, p. 29, sep. 1995.

DE LEÓN, I. Diálogo sobre propiedad intelectual y desarrollo sostenible, ICTSD-UNCTAD, CEIDIE-SPDA, 22-23-03-2004. Disponible en

< http://www.iprsonline.org/unctadictsd/dialogue/2004-03-22/2004-03-22_docs.htm>

Derechos de la propiedad intelectual: integrando los derechos de propiedad y las políticas de desarrollo. Buenos Aires: Ciudad Argentina, 2005. (Temas de Derecho Industrial y la Competencia, n. 7).

DREXL, L. La evolución de los Trips: Hacia un multilateralismo flexible, ponencia 
presentada en el Seminario de la Asociación Internacional de Derecho Económico, Octubre 2005

DUTFIELD, G. Repartiendo beneficios da biodiversidade: qual o papel do sistema de patentes. PLATAU, A. F.; VARELLA, M. Días. (Org). Diversidade biológica e conhecimento tradicional, Belo Horizonte: Del Rey, 2004.

ECHEVERRÍA, J. La revolución tecno-científica. Madrid: FCE, 2003.

FRANCESCHI, M. Droit et marchandisation de la connaissance sur les gens humains. Paris: CNRS, 2004.

FRISON ROCHE, M. A. Les biens de'humanite débouche de la querelle entre marché et patrimonie. In: Vivant, M. (Org.). Propiété intellectuelle et mondialization. París: Dalloz, 2004.

GHIDINI, G. Aspectos actuales del derecho industrial. Granada: Comares, 2002.

GROS, F. ; Jacob, F. ; Royer, P. Sciences de la vie et societé. Paris: Seuil, 1979.

HOTTOIS, G. El paradigma bioético. Madrid: Anthropos, 1991.

KUCHIRO Hayashi. In: Barros Platiau; VARELLA, Días M. (Org.). Diversidade biológica e conhecimentos tradicionais. Belo Horizonte: Del Rey, 2004.

LESSER, W. Sustainable use of genetic resources and the reconvention on biological diversity. New York: CAB International, 1998.

OST, F. Naturaleza y derecho. Bilbao: Mensajero, 1996.

PÉREZ SALOM, J. R. Recursos genéticos, biotecnología y derecho internacional. Navarra: Aranzadi, 2002.

PETERSON, L. E. Bilateral investment treaties and development policies-making. International Institute for Sustainable Development, 2004. Disponível em: <www.iisd.org>.

PROPIEDAD intelectual y políticas de desarrollo. Buenos Aires: Ciudad Argentina, 2005. (Temas de derecho industrial y de la competencia).

REMICHE, B.: Revolucao tecnológica, globalizacao e diritto des patentes. In : Vivant, M. (Org.). Propiété intellectuelle et mondialization. París: Dalloz, 2004.

ROFFE, P. El Acuerdo de los ADPIC y la transferencia de tecnología. Ponencia presentada al Seminario de la Asociación Internacional de Derecho Económico, realizado en Buenos Aires, en octubre de 2005 (mimeo).

RUIZ, M. Protección sui géneris de conocimientos indígenas en la Amazonia. Lima: Sociedad Peruana de Derecho Ambiental, 2002. 
SACHS, J. A new map of the world. The Economist. Disponível em: $<$ http://www.cid.harvard. edu/cidinthenews/articles/Sachs_on_globalisation.htm>.

STIGLITZ, J. E. El conocimiento como un bien público mundial. In: Kaul I, Grunberg I, Stern M (eds.). Global public goods. UNDP. New York: Oxford University Press; 1999.

TALLACCHINI, M.C. Umbrales de artificialidad: las oscilaciones de la patentabilidad genética. Revista de Derecho y Genoma Humano, Bilbao, n. 18, p. 115, ene./jun. 2003.

THUROW, Needed. The new system of intellectual property right. Harvard Business Review, [S.l.], p. 103, Sept.-Oct.1997.

UNCTAD. Intelectual property rights. Implications for development. Geneve, 2003.

VANDANA SHIVA. ¿Proteger o expoliar?: los derechos de propiedad intelectual. Barcelona: Intermon, 2003. (Colección de libros de encuentro).

VARELLA, M Días. Direito internacional económico ambiental. Belo Horizonte: Del Rey, 2004.

Prismas: Direito, Políticas Públicas e Mundialização

http://www.mestrado.uniceub.br/revistamestrado/

Artigo recebido em 06/03/2006 e aceito para publicação em 13/05/2006

A revista Prismas: Direito, Políticas Públicas e Mundialização destina-se à publicação de artigos relacionados com a área jurídica, tem o propósito de difundir as reflexões dos pesquisadores, docentes, discentes, profissionais e estudantes da área de Ciências Jurídicas.

Os artigos são avaliados mediante processo de revisão por pares e deverão contemplar as reflexões que dizem respeito ao estudo do Direito, das Relações Internacionais e das Políticas Públicas. 